\title{
Application of the Bolton Relay Device for Thoracic Endografting In or Near the Aortic Arch
}

\author{
Vincent Riambau, MD, PhD* \\ Vascular Surgery Division, Thorax Institute, Hospital Clinic of Barcelona, Barcelona, Spain
}

\begin{abstract}
Endovascular correction of aortic arch pathology remains a challenge, with a variety of techniques proposed over the years to minimize complications and enhance the probability of a successful result. A variety of approaches have been developed in order to deal with the aortic arch pathology and its idiosyncrasies. We review potential interventional techniques for the repair of aortic arch pathologies, beginning with conventional aortic arch surgery, followed by hybrid treatments and those along the endovascular spectrum (parallel and fenestrated endografts, scalloped endografts, and ascending and new branched endografts). We finish with an overview of all the Bolton Medical (Barcelona, Spain and Sunrise, FL, USA) thoracic platforms. Endovascular techniques show acceptable results in selected cases. Both proximal Bolton Relay configurations (with and without a bare stent) offer conformability and accuracy on deployment with very low rates of stroke. Fenestrated and scalloped designs are also useful for selected cases. Ascending and branched Bolton devices are very promising platforms for a serious, full endovascular approach to the aorta.

Copyright $\odot 2015$ Science International Corp.
\end{abstract}

\section{Key Words}

Arch • Endovascular treatment • Endograft

\section{Introduction: Aortic Arch-Related Pathologies}

There are an increasing number of patients with thoracic aortic pathology. Enlargement of the thoracic aorta is an increasingly recognized condition that

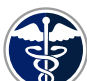

Fax +1 2037853552

E-Mail: aorta@scienceinternational.org

http://aorta.scienceinternational.org

\author{
(c) 2015 AORTA \\ Published by Science International Corp. \\ ISSN 2325-4637 \\ Accessible online at: \\ http://aorta.scienceinternational.org
}

is usually diagnosed incidentally on imaging studies performed to evaluate unrelated conditions. Main pathologies of the thoracic aorta, including the arch section, include aneurysms (and sometimes pseudoaneurysms), dissections, penetrating ulcers, and intramural hematomas (IMHs).

Aneurysms along the arch often develop over many years without symptoms; however, they are a serious pathology, with an incidence around 5 to 10 cases per 100,000 patients/year [1]. Arch aneurysms are dangerous health issues, which often require urgent surgical interventions. The prevalence of arch aneurysms may be at least 3-4\% of patients older than 65 years. Aortic aneurysms are the 18th leading cause of death in the USA and the 15th among individuals older than 65 years. Aortic aneurysms cause about 13,000 deaths per year in the USA [2]. Thoracic aneurysms are mainly caused by atherosclerosis and other degenerative diseases of the aorta, and have been historically treated with highly invasive surgery. Due to the significant risks associated with thoracotomy, alternative approaches to treat aortic disease have been developed.

Aortic dissections are relatively uncommon, with a documented incidence of 10-20 cases per million population per year [3]. However, aortic dissection is a serious health condition, with extremely high mortality rates, affecting both young and elderly people. Reported incidence rates are probably underestimates of the true incidence, because of difficulties in diagnosis (symptoms of aortic dissection may mimic those of other diseases, often leading to

\footnotetext{
* Corresponding Author:

Vincent Riambau, MD, PhD

Thorax Institute, Hospital Clinic

University of Barcelona

Villarroel 170, 08036 Barcelona, Spain

Tel: +34 932275515, Fax: +34 932275749, E-mail: vriambau@gmail.com, vriambau@clinic.ub.es
} 
errors in diagnosis). The incidence of aortic dissection appears to have increased over time [3]. Hypertension has been considered the most important risk factor for this condition, which most frequently occurs in men between 60 and 70 years of age [4]. Patients with untreated dissections have a high mortality rate, particularly if the dissection involves the ascending aorta. The mortality rate of patients with untreated dissections can be as high as $90 \%$ within 1 week to 3 months of diagnosis [4].

Penetrating ulcers and IMHs are radiologically distinct from classic aortic dissection. These variants of the acute aortic pathology are prone to rupture. A rupture incidence between $21-47 \%$ has been documented. Untreated patients with IMHs can show mortality rates at 30 days of $46 \%$. The clinical impact of Type A IMH (proximal) tends to have a high frequency of complications (dissection or rupture) and even death. Therefore, urgent treatment is required. Surgery has also been the standard treatment of penetrating ulcers; however, it has been associated with high morbidity and mortality (9-38\% of cases) [4-6]. In the case of IMHs, monitoring may be the best approach in cases of nonsevere symptoms, given the risk associated with surgery.

Traditionally, reports using open surgical techniques to treat the aortic arch and ascending aorta show rates of mortality, which range from $0 \%$ to $16.5 \%$ and stroke rates from $2 \%$ to $18 \%$ [7].

The correction of aortic arch pathology remains a challenge, with a variety of techniques proposed over the years to minimize complications and enhance the probability of a successful result [8]. In this light, a variety of approaches have been developed in order to deal with aortic arch pathology and its idiosyncrasies.

\section{Treatment: Conventional to State-of-the-Art Endovascular Solutions}

\section{Conventional Treatments: Aortic Arch Surgery}

This technique, implying replacement of aortic arch portions by synthetic grafts to restore blood flow through the aorta and all branch vessels, has improved during recent years. Different surgical techniques of extracorporeal circulation with selective supraaortic trunk perfusion appear to decrease cerebral ischemia. However, significant rates of mortality and morbidity persist $[8,9]$.

The future of aortic surgery will be influenced by endovascular advances. Despite an interest in developing a unique endovascular approach for the aortic arch, its limitations will probably slow an endovascular replacement of open aortic arch surgery. In addition, some advances of open surgery, including new strategies for cerebral protection (i.e., the use of antegrade cerebral perfusion and the use of more moderate temperatures for hypothermic systemic circulatory arrest) have been made in recent years [4,9].

\section{Hybrid Treatments: A Bridge from Surgery to an Endo-} vascular Approach

Hybrid repair, usually constituting a combination of open supraaortic branch revascularization before the arch and endovascular aortic stent-graft repair, is an alternative option to open surgery for selected patients.

Total arch debranching procedures have been described as safe and relatively less invasive in high-risk patients [10-12].

The few studies showing hybrid repair of aortic arch aneurysms in samples of fewer than 10 cases showed still-relevant adverse consequences (i.e., perioperative mortality or stroke from $0 \%$ to $25 \%$ ) [13].

A recent hybrid series for aortic disease focusing on techniques to avoid endoleaks [14] showed $0 \%$ incidences of neurologic events and endoleaks. Previous experiences reported endoleaks in 5\% to $30 \%$ of cases [15-17].

Different hybrid alternatives have been proposed to treat various aortic pathologies [18], with some optimizing the fixation of the endovascular stent graft [8].

\section{Endovascular: A Rainbow of Solutions for the Arch}

The aortic arch is the last frontier for endovascular treatment. This segment presents specific challenges to endovascular repair. In recent years, the number of thoracic endovascular procedures has risen $[18,19]$.

An endovascular procedure has a lower mortality rate compared to open surgical repair and is now being used in individuals with conditions that make them high-risk patients for open surgery. 
Endovascular repair results in excellent midterm protection from aortic-related mortality, regardless of presenting pathology and comorbidities. There is a small, but significant, persistent risk of aorta or aneurysm rupture that is higher than that of an open-surgery aneurysm approach [20].

Parallel Stent-Grafts: The Chimney or Snorkel Technique. This technique, consisting of endovascular stent placement parallel to the main aortic stent graft in order to preserve or rescue flow to aortic branch vessels and allow proximal extension of endograft fixation zones, has been used in a variety of aortic arch pathologies and is feasible and safe in midterm follow up [21].

This technique is less challenging compared to fenestrated and branched endografting [22] and can be used with a variety of stents, making it applicable in urgent situations.

The incidence of endoleaks and strokes during the perioperative period is $21.6 \%$ and $7.8 \%$, respectively [23]. A limitation is that the stents may become obstructed, resulting in stenosis. Future studies should evaluate long-term graft durability and techniques for fixation to the aortic arch.

Fenestrations. The thoracic aorta has a three-dimensional angulation and an anatomical peculiarity of three vessels branching at narrow intervals along the arch. Fenestrated endovascular aortic repair enables the continuation of blood flow to the arteries through holes in the graft.

Deployment of the endograft in the arch is necessary to adjust the fenestrations to correspond to each ostium of the vessels. Some second-generation devices have obtained high-quality adaptability to the arch curvature by the use of new materials, shortlength stent elements, and the possibility of an expansion stent system.

The need to maintain perfusion of the branch arteries has limited application of endovascular techniques for treatment of more complex aneurysms. The next generation of precurved fenestrated endografts appears to be a good option for aortic arch aneurysms with a less than $15-\mathrm{mm}$ proximal sealing zone. These devices have a significant advantage in cases where the landing zones have a short neck [24].
Scallops. A scalloped device may be a treatment option for urgent aortic arch and aneurysms in the distal aortic proximal-descending aorta. This technique does not require surgical revascularization, providing an adequate landing zone while preserving flow (via the scallop) to the left upper limb and posterior cerebral circulation. Limitations of these devices include a possible lack of accuracy of deployment in the diseased arch and the elapsed time for the device customization (product availability of the custom made device takes 3 weeks on average). Variability of the origin of the left subclavian artery may limit the feasibility of use of ready-made scalloped thoracic stent-graft devices.

New Branched Endografts. New endografts with modular, small branches for aortic arch branches that are flexibly adapted and connected to the stent implanted into the aortic arch appear to be a promising future approach to aortic arch diseases. Different custom-made and off-the-shelf models have been developed [25-28] with good initial outcomes.

The characteristics of the modular branched grafts are markedly different from previous techniques, allowing precise, optimal positioning of the stent graft and branches.

New-generation stent grafts have good early clinical and radiologic outcomes and avoid the need for open surgery. The off-the-shelf branched solution eliminates adjunctive procedures (hybrid repair, extra-anatomic bypasses, and chimneys). However, demonstration of durability for off-the-shelf branched stent grafts is essential for securing longterm outcomes.

\section{Bolton Medical Approaches: Focus on the Aortic Arch}

This part of the report concerns the Relay family of stent graft products for Thoracic Endovascular Aneurysm Repair (TEVAR), commercially available since receiving CE approval in 2005, as well as the Treovance stent grafts for Endovascular Aneurysm Repair (EVAR), receiving the CE mark in 2013 (Bolton Medical, Barcelona, Spain and Sunrise, Florida, USA). 


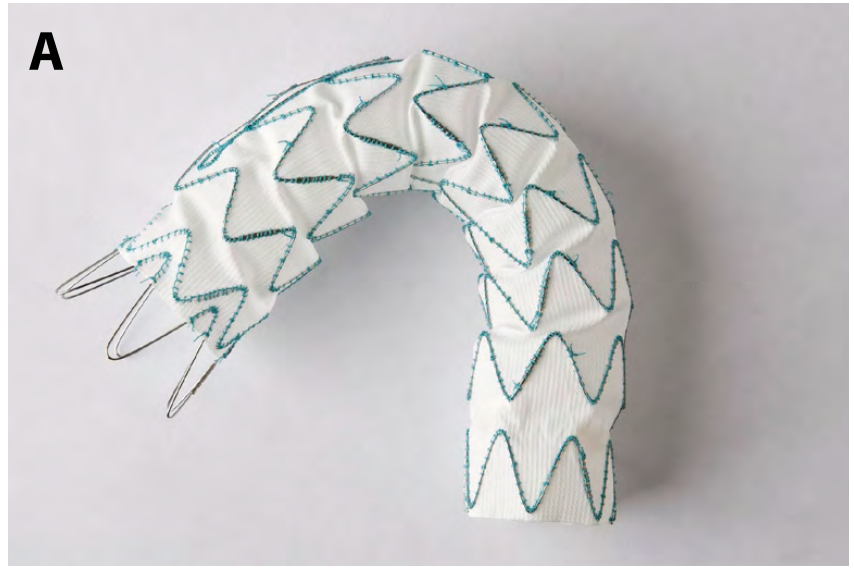

B

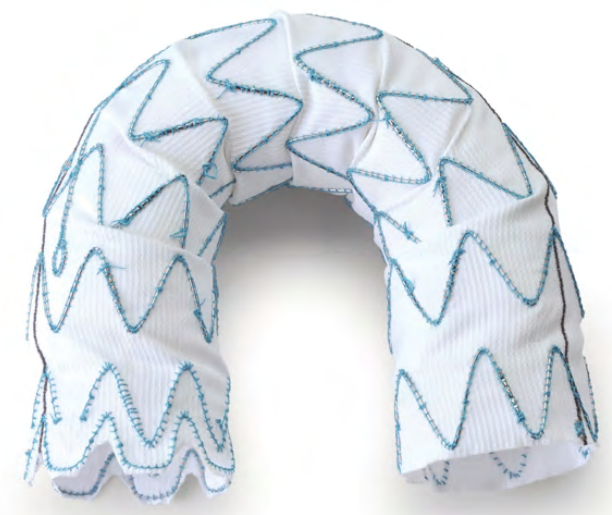

Figure 1. Two proximal edges are available: With proximal bare stent configuration (Relay) (A) and without bare stent (Relay NBS) (B).

The Relay stent grafts are particularly designed to favor tracking, navigation through and upon landing of the device in the aortic arch, even in challenging anatomies that present acute curvatures and angles, or unfavorable proximal landing zones. The following are the main features underlying performance of the Relay grafts in the aortic arch and ascending aorta segments:

\section{Stent Graft}

- Presence of an outer curved Nitinol bar (S-bar) that allows for the gentle conformability of the device along the three-dimensional anatomy of the aortic arch.

- Design of the proximal stent graft with 2 configurations to align to the center of the aortic arch : bare stent (Relay) and without bare stent (Relay NBS) (Figure $1 \mathrm{~A}$ and $\mathrm{B}$ ).

Essentially, the device adapts to the aortic anatomy without modifying the vessel morphology.

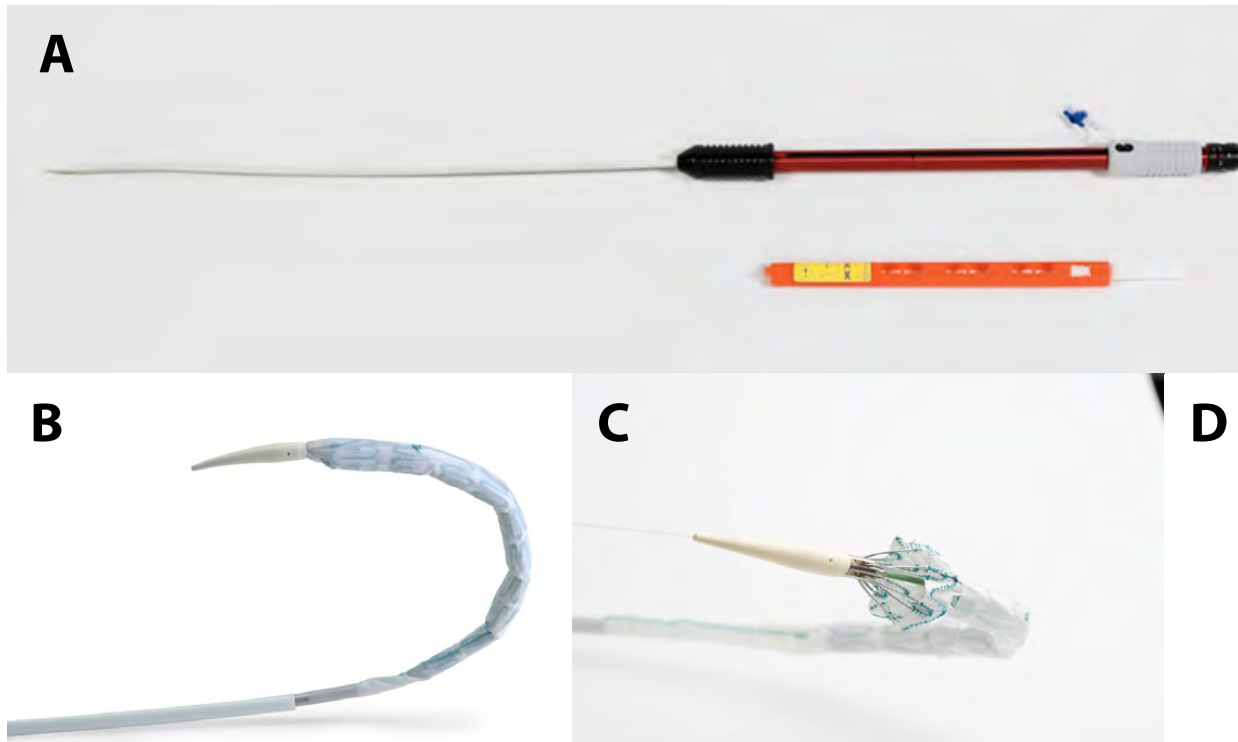

Figure 2. Overall view of the delivery system (A). The polyester sheath offers more flexibility (B). Both proximal end configurations, with $(C)$ and without $(D)$ bare stent, have a capture system for a sequential deployment of the endograft. 
Table 1. Summary of RESTORE early Results for arch pathology.

\begin{tabular}{llll}
\hline Landing Zone & $\begin{array}{l}\text { Z0 (\%) } \\
\mathbf{n = 2 2}\end{array}$ & $\begin{array}{l}\mathbf{Z 1}(\%) \\
\mathbf{n}=\mathbf{3 6}\end{array}$ & $\begin{array}{l}\mathbf{Z 2}(\%) \\
\mathbf{n}=\mathbf{7 4}\end{array}$ \\
\hline Etiology & & & \\
Aneurysm & $15(68.2)$ & $17(47.2)$ & $32(43.2)$ \\
Dissection & $7(31.8)$ & $17(47.2)$ & $22(29.7)$ \\
Traumatic & 0 & $1(2.8)$ & $15(20.3)$ \\
False anastomotic & 0 & $1(2.8)$ & $4(5.4)$ \\
Mycotic & 0 & 0 & $1(1.4)$ \\
& & & \\
Technical success & $20(90.9)$ & $36(100)$ & $72(97.3)$ \\
Endoleak rate & $1(4.5)$ & $1(2.8)$ & $5(6.7)$ \\
Device related complic. & $2(9.1)$ & $2(5.6)$ & $6(.1)$ \\
Stroke & $1(4.5)$ & 0 & $1(1.3)$ \\
Death (in hospital) & $1(4.5)$ & $4(11.1)$ & $6(8.1)$ \\
Conversion to open surgery & $1(4.5)$ & $1(2.8)$ & 0 \\
\hline
\end{tabular}

\section{Delivery Device}

A dual (inner and outer) sheath system provides sufficient pushability in the lowest aortic segment (from the vascular access site to the diaphragm), whereas the flexible Nitinol-made inner tube provides trackability to the operator, even in acute (e.g., Gothic arch) and complicated curves (Figure 2 A-D).

There are four differently designed solutions among Bolton Medical grafts to be considered when treating the aorta from the aortic valve to the aortic isthmus: Relay and Relay NBS standard (CE mark) stent grafts and three custom-made tailored devices-Proximal Scalloped Relay, Ascending Relay, and Branched Relay-when commercially available products are not sufficient to address a specific anatomical limitation.

Relay and Relay NBS. More than 15,000 Relay and Relay NBS stent grafts have been implanted worldwide so far. The treatment indication described in the instructions for use for the use of these devices in the aorta includes the treatment of aneurysm, pseudoaneurysm, dissection, intramural hematoma, and atherosclerotic ulcers. The design features described
Table 2. Summary of RESTORE II early Results for arch pathology.

\begin{tabular}{llll}
\hline Landing Zone & $\begin{array}{l}\text { Z0 (\%) } \\
\mathbf{n = 1 0}\end{array}$ & $\begin{array}{l}\text { Z1 (\%) } \\
\mathbf{n = 1 5}\end{array}$ & $\begin{array}{l}\text { Z2 (\%) } \\
\mathbf{n}=\mathbf{5 7}\end{array}$ \\
\hline Etiology & & & \\
Aneurysm & $7(70.0)$ & $13(86.7)$ & $18(31.6)$ \\
Dissection & $3(30.0)$ & $2(13.3)$ & $39(68.4)$ \\
Traumatic & 0 & 0 & 0 \\
False anastomotic & 0 & 0 & 0 \\
Mycotic & 0 & 0 & 0 \\
& & & \\
Technical success & $10(100.0)$ & $15(100.0)$ & $54(94.7)$ \\
Endoleak rate & 0 & 0 & $7(12.3)$ \\
Device related complic. & 0 & 0 & $4(7,0)$ \\
Stroke & $1(10.0)$ & 0 & 0 \\
Death (in hospital) & 0 & 0 & $3(5.3)$ \\
Conversion to open surgery & 0 & 0 & 0 \\
\hline
\end{tabular}

Table II includes results similar to Table 1 but for the cases included in RESTORE II (worldwide PMS registry). Only elective cases presenting aneurysm or dissection have been included in the study.

above favor the use of Relay and Relay NBS in aortic arch lesions.

Two major international post-market data registries, RELAY Endovascular Registry for Thoracic Disease (RESTORE) and RESTORE II, have been carried out to obtain clinical feedback when using the products in a "real-life" situation, including a variety of different aortic pathologies and patient conditions (e.g., post-trauma patients) [29,30]. Table 1 summarizes the operative results obtained with Relay/Relay NBS in aortic arch lesions in a cohort of 304 patients (RESTORE, European Registry).

Table 2 includes results similar to Table 1 but for cases included in RESTORE II (worldwide post market surveillance registry). Only elective cases presenting with aneurysm or dissection were included in the study.

These results from aortic arch surgery are considered satisfactory. The low rate of complications, especially for stroke $(1.5 \%$ and $1.2 \%$, for RESTORE and RESTORE II, respectively), suggests that both the 
stent graft and the delivery device are effective for this aortic segment.

Proximal Scalloped Relay. Proximal scalloped as well as ascending and branched Relay devices are custom-made, designed, and exclusively manufactured under medical prescription. This process requires about 2 to 3 weeks.

Proximal scallops are sized depending on the measurement of the upper trunk (or trunks) to be included in the scallop. A lateral positioning of the scallop is also a good solution when the upper branch does not arise from the center plane of the aorta.

Strategically placed tubular radiopaque markers are positioned surrounding the scallop. This feature is helpful when manipulating the delivery device for effective matching of the opening with the ostium of the upper branch. The X-ray tube is angulated and changed from left-anterior-oblique to right-anterior-oblique projections to assure both the longitudinal and lateral positioning of the scallop.

Control of systolic arterial pressure is another strongly recommended maneuver during the deployment of the stent graft. Rapid pacing is probably the most effective technique to obtain a near-zero blood pressure level.

Some technical restrictions apply when designing the customization, specifically related to the

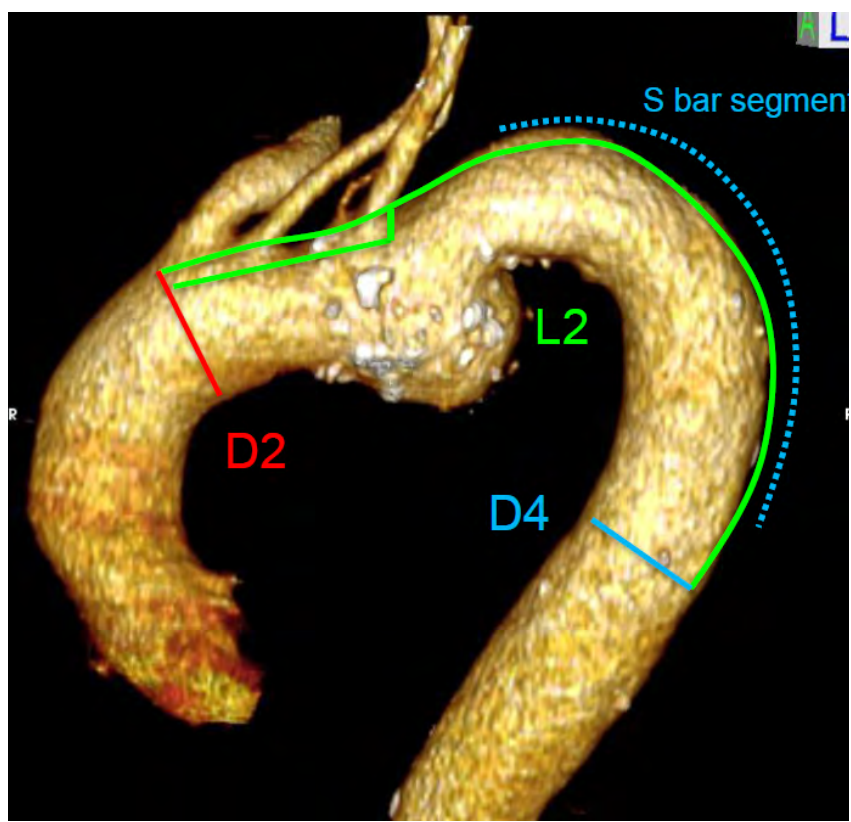

Figure 3. Planning sketch of proximal scallop endograft. D2 is proximal diameter; D4 is distal diameter and L2 is the total length.

width of the scallop but not the length, which can be as long as needed to include one, two, or even three upper trunks in the "window." Scallops as long as $55 \mathrm{~mm}$ in length have been manufactured in cases where the inclusion of all the upper trunks was required (Figure 3).
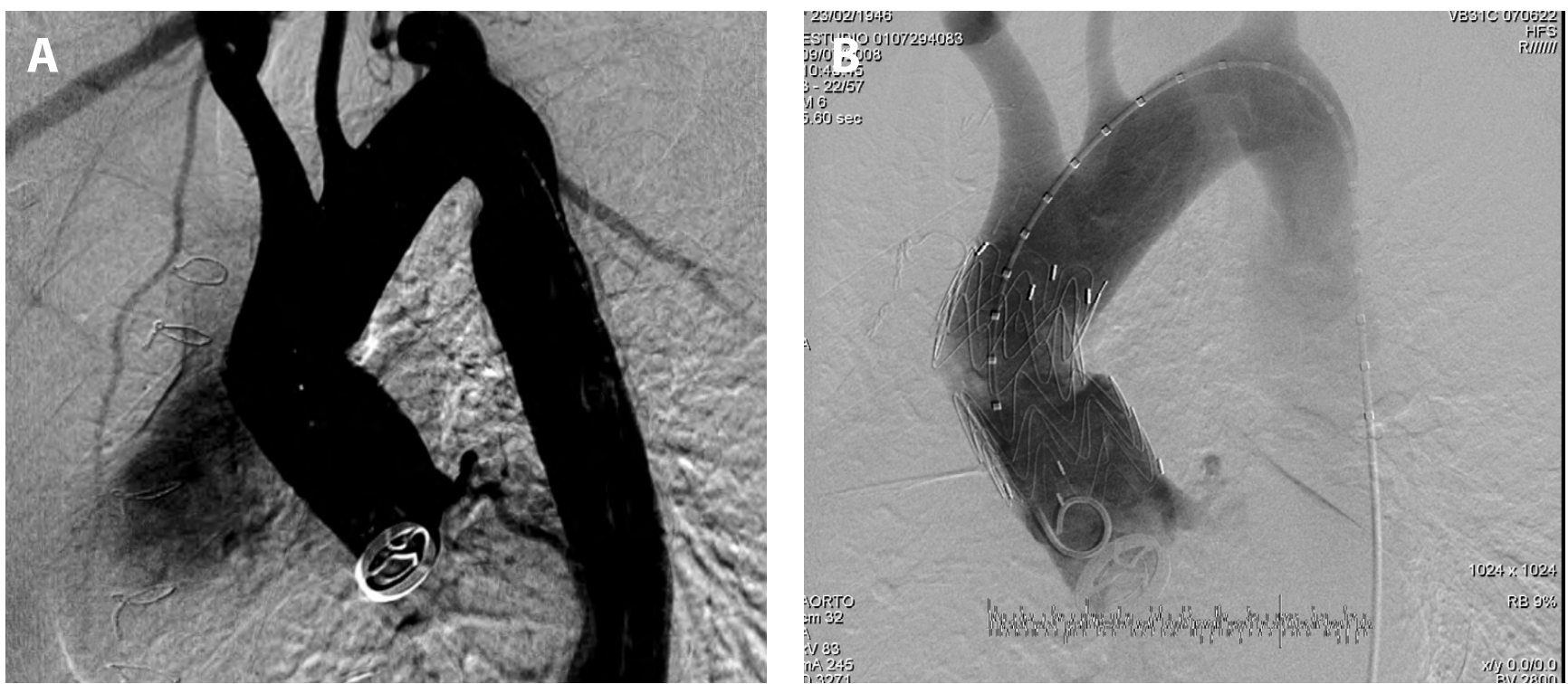

Figure 4. Example of a pseudoaneurysm of the ascending aorta after cardiac surgery (A) treated with a Bolton Medical device (B). 
Table 3. Summary of Relay double Branched endograft early results.

\begin{tabular}{lllll}
\hline \# & Age/Sex & Pathology & Endoleak & Intraoperative \\
Complication
\end{tabular}

F: Female; M: Male; TAA: Thoracic Aortic Aneurysm; N: None; RSCA: Right Subclavian Artery; LCCA: Left Common Carotid Artery; LV: Left Ventricle. Patients status by August 2014: ${ }^{1}$ Alive. ${ }^{2}$ Dead caused

by multiple stroke.

International clinical studies (retrospective and prospective) are ongoing in order to collect clinical data to confirm the good results published by several authors experienced with this device [31].

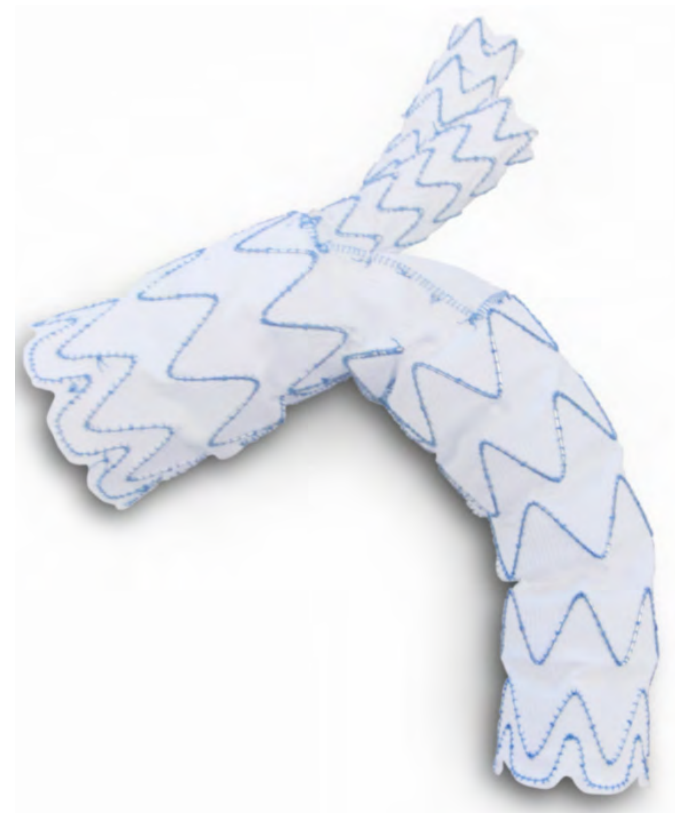

Figure 5. Overview of a double branched Bolton Medical endograft for the aortic arch.

Relay for Ascending Aorta. As short as 4-7-cm long, customized Relay devices to treat the ascending aorta have been designed and implanted using its nonbare stent configuration to avoid any interference with the aortic valve (Figure 4).

The anatomical limits to take into account in the ascending aorta are the coronary ostia at the proximal end and the brachiocephalic trunk at the distal end. Thus, a careful analysis of the aortic anatomy when making pre-case assessments and measurements is essential.

As for the proximal scalloped devices, rapid pacing is recommended for the treatment of the ascending aorta; one single systolic peak could incite a partial migration of the device and the unintentional covering of the brachiocephalic trunk.

Branched Relay. A new device with branches for the upper trunks has recently been utilized in patients [32].

The device is based on the Relay NBS platform but incorporates a "roof-positioned" aperture connected to two internal tunnels for easy cannulation of the two branches (Figure 5).

Technically, stent-graft positioning is facilitated by the flexibility of the delivery device's inner Nitinol hy- 
potube (as it is for the ascending Relay). The presence of pared "driving-wires" (support wires) allows for a precise proximal landing in Zone 0 and for progressive apposition of the proximal stent-graft segment against the aortic wall.

One of the main concerns in this type of device is potential dislocation of the branches during deployment due to the asynchronous motion of the aorta. In this case, there is a locking mechanism (inner dull barbs in the internal tunnels) that prevents separation of the bridging stent.

The operative results with the dual branched device in clinical application are presented in Table 3.

\section{Conclusions}

Aortic arch repair is a challenging surgical procedure. Endovascular techniques show acceptable results in selected cases. A total endovascular approach with branched endografts will be a useful alternative for high-risk patients. Both proximal Bolton Relay configurations (with and without a bare stent) offer conformability and accuracy on deployment with low rates of stroke. Fenestrated and scalloped designs are useful for selected cases. Ascending and branched Bolton devices are promising platforms for a full endovascular approach to the aorta.

\section{Acknowledgments}

We would like to thank Roger Ferrer MSc (Bolton Medical, Barcelona) for providing all clinical data and Emili González-Pérez PhD, MSc (TFS, Barcelona) and Roger for their help during the writing process.

\section{Conflict of Interest}

The author is consultant and proctor for Bolton Medical, Medtronic Inc and WL Gore \& Associates. Also he is proctor for Cook Medical.

\section{Comment on this Article or Ask a Question}

\section{References}

1. Booher AM, Eagle KA. Diagnosis and management issues in thoracic aortic aneurysm. Am Heart J. 2011;162:38-46. DOI: 10.1016/j.ahj.2011.04.010

2. WISQARS Leading Causes of Death Reports, 1999 - 2007. National Center for Injury Prevention and Control. http://webappa.cdc.gov/sasweb/ncipc/leadcaus 10 . html. Updated June, 2010.

3. Dake M, Kato N, Mitchell S, Semba C, Razavi $M$, Shimono $T$, et al. Endovascular stent-graft placement for the treatment of acute aortic dissection. N Engl J Med. 1999;340:1546-1552. DOI: 10.1056/ NEJM199905203402004

4. Kouchoukos NT, Dougenis D. Surgery of the thoracic aorta. N Engl J Med. 1997;336:1876-89. DOI: 10.1056/ NEJM199706263362606

5. LeMaire $S$, Price $M$, Parenti J, Johnson $M$, Lay A, Preventza O, et al. Early outcomes after aortic arch replacement by using the Y-graft technique. Ann Thorac Surg. 2011;91:700-707. DOI: 10.1016/j.athoracsur.2010.11.008

6. Kos X, Bouchard L, Otal P, Chabbert V, Chemla $P$, Soula $P$, et al. Stent-graft treatment of penetrating thoracic aortic ulcers.
J Endovasc Ther. 2002;9:1125-1131. DOI: 10.1583/1545-1550-9.sp3.25

7. Moon MC, Morales JP, Greenberg RK. The aortic arch and ascending aorta: are they within the endovascular realm? Semin Vasc Surg. 2007;20:97-107. DOI: 10.1053/j. semvascsurg.2007.04.007

8. Apostolakis E, Akinosoglou K. The methodologies of hypothermic circulatory arrest and of antegrade and retrograde cerebral perfusion for aortic arch surgery. Ann Thorac Cardiovasc Surg. 2008;14:138-148. PMID: 18577891

9. Spielvogel D, Etz CD, Silovitz D, Lansman SL, Griepp RB. Aortic arch replacement with a trifurcated graft. Ann Thorac Surg. 2007;83:S791-S795. DOI: 10.1016/j.athoracsur.2006.11.015

10. Yoshida RA, Kolvenbach R, Yoshida WB, Wassijew S, Schwierz E, Lin F. Total endovascular debranching of the aortic arch. Eur J Vasc Endovasc Surg. 2011;42:627630. DOI: 10.1016/j.ejvs.2011.06.054

11. Moulakakis KG, Mylonas SN, Markatis F, Kotsis T, Kakisis J, Liapis CD. A systematic review and meta-analysis of hybrid aortic arch replacement. Ann Cardiothorac Surg. 2013;2:247-260. DOI: 10.3978/j.issn.2225-
319X.2013.05.06

12. Ferrero $E$, Ferri $M$, Viazzo $A$, Robaldo $A$, Zingarelli $E$, Sansone $F$, et al. Is total debranching a safe procedure for extensive aortic-arch disease? A single experience of 27 cases. Eur J Cardio-Thorac Surg. 2012;41:177-182. DOI: 10.1016/j. ejcts.2011.05.058

13. Chiesa R, Melissano G, Tshomba Y, Civilini E, Marone EM, Bertoglio L, et al. Ten years of endovascular aortic arch repair. J Endovasc Ther. 2010;17:1-11. DOI: 10.1583/092884.1

14. Gelpi G, Vanelli P, Mangini A, Danna P, Contino $M$, Antona $C$. Hybrid aortic arch repair procedure: reinforcement of the aorta for a safe and durable landing zone. Eur J Vasc Endovasc Surg. 2010;40:709-714. DOI: 10.1016/j.ejvs.2010.08.017

15. Gottardi R, Funovics M, Eggers N, Hirner A, Dorfmeister $M$, Holfeld J, et al. Supra-aortic transposition for combined vascular and endovascular repair of aortic arch pathology. Ann Thorac Surg. 2008;86:1524-1529. DOI: 10.1016/j.athoracsur.2008.06.075

16. Piffaretti G, Mariscalco G, Lomazzi C, Rivolta N, Riva F, Tozzi M, et al. Predictive factors for endoleaks after thoracic aortic aneu- 
rysm endograft repair. J Thorac Cardiovasc Surg. 2009;138:880-885. DOI: 10.1016/j. jtcvs.2009.02.024

17. Hughes GC, Daneshmand MA, Balsara KR. "Hybrid" repair of aneurysms of the transverse aortic arch: midterm results. Ann Thorac Surg. 2009;88:1882-1887. DOI: 10.1016/j.jvs.2010.04.004

18. Scali S, Goodney P, Walsh D, Travis L, Nolan B, Goodman D, et al. National trends and regional variation of open and endovascular repair of thoracic and thoracoabdominal aneurysms in contemporary practice. J Vasc Surg. 2011;53:1499-1505. DOI: 10.1016/j.jvs.2011.02.014

19. Goodney P, Travis L, Lucas F, Fillinger M, Goodman D, Cronenwett J, et al. Survival after open versus endovascular thoracic aortic aneurysm repair in an observational study of the Medicare population. Circulation. 2011;124:2661-2669. DOI: 10.1161/ circulationaha.111.033944

20. Patterson B, Holt P, Nienaber C, Cambria R, Fairman $\mathrm{R}$, Thompson M. Aortic pathology determines midterm outcome after endovascular repair of the thoracic aorta: report from the Medtronic Thoracic Endovascular Registry (MOTHER) database. Circulation. 2013;127:24-32. DOI: 10.1161/circulationaha.112.110056

21. Gehringhoff B, Torsello G, Pitoulias GA, Austermann M, Donas KP. Use of chimney grafts in aortic arch pathologies involving the supra-aortic branches. J Endovasc Ther. 2011;18:650-655. DOI: 10.1583/11-3504.1

22. Amiot $S$, Haulon $S$, Becquemin JP, Magnan $P E$, Lermusiaux $P$, Goueffic $Y$, et al. Fenestrated endovascular grafting: the French multicentre experience. Eur J Vasc Endovasc Surg. 2010;39:537-544. DOI: 10.1016/j. ejvs.2009.12.008

23. Yang J, Xiong J, Liu X, Jia X, Zhu Y, Guo W. Endovascular chimney technique of aortic arch pathologies: A systematic review. Ann Vasc Surg 2012;26:1014-1021. DOI: 10.1016/j.avsg.2012.05.014

24. Azuma T, Yokoi Y, Yamazaki K. The next generation of fenestrated endografts: results of a clinical trial to support an expanded indication for aortic arch aneurysm treatment. Eur J Cardio-Thorac Surg Off J Eur Assoc Cardio-Thorac Surg. 2013;44:e156e163. DOI: 10.1093/ejcts/ezt241

25. Inoue K, Hosokawa H, Iwase T, Sato M, Yoshida Y, Ueno K, et al. Aortic arch reconstruction by transluminally placed endovascular branched stent graft. Circulation. 1999; 100: II-316-li-321. DOI: 10.1161/01. cir.100.suppl_2.ii-316

26. Schneider DB, Curry TK, Reilly LM, Kang JW, Messina LM, Chuter TAM. Branched endovascular repair of aortic arch aneurysm with a modular stent-graft system. J Vasc Surg. 2003;38:855. DOI: 10.1016/s07415214(03)01024-3

27. Chuter TAM, Schneider DB, Reilly LM, Lobo EP, Messina LM. Modular branched stent graft for endovascular repair of aortic arch aneurysm and dissection. J Vasc Surg. 2003;38:859-863. DOI: 10.1016/s07415214(03)01023-1

28. Piffaretti G, Rivolta N, Fontana F, Carrafiello G, Mariscalco G, Castelli P. Aortic arch aneurysm repair with a new branched device. J Vasc Surg. 2013;57:1664-1667. DOI: 10.1016/j.jvs.2012.10.080
29. Riambau V, Zipfel B, Coppi G, Czerny M, Tealdi D, Ferro $C$, et al. Final operative and midterm results of the European experience in the RELAY Endovascular Registry for Thoracic Disease (RESTORE) study. J Vasc Surg. 2011;53:565-573. DOI: 10.1016/j.jvs.2010.09.050

30. Zipfel B, Czerny M, Funovics M, Coppi G, Ferro $\mathrm{C}$, Rousseau $\mathrm{H}$, et al. Endovascular treatment of patients with types $A$ and $B$ thoracic aortic dissection using Relay thoracic stent-grafts: Results from the RESTORE Patient Registry. J Endovasc Ther. 2011;18:131-143. DOI: 10.1583/10$3233 \mathrm{mr} .1$

31. Kashef $E$, Aldin Z, Jenkins M, Gibbs R, Bicknell C, Cheshire N, et al. Scalloped thoracic stent-graft for treatment of aortic arch aneurysms with unfavourable landing zones. Cardiovasc Intervent Radiol. 2011;34:845851. DOI: 10.1007/s00270-011-0099-9

32. Yunoki J, Kuratani T, Shirakawa Y, Torikai K, Shimamura K, Kin K, et al. Clinical experience with the RELAY NBS PLUS stent-graft for aortic arch pathology. Surgery Today 2014;44:2263-2268. DOI:10.1007/s00595014-0851-2

Cite this article as: Riambau V. Application of the Bolton Relay Device for Thoracic Endografting In or Near the Aortic Arch. AORTA. 2015;3(Issue 1): 16-24. DOI: http://dx.doi.org/10.12945/j. aorta.2015.14-050 